\title{
Supporting the Complex Social Lives of New Parents
}

\author{
Austin L. Toombs ${ }^{1,2}$, Kellie Morrissey ${ }^{2}$, Emma Simpson $^{2}$, \\ Colin M. Gray ${ }^{1}$, John Vines ${ }^{3}$, Madeline Balaam ${ }^{4}$ \\ ${ }^{1}$ Purdue University, West Lafayette, IN, USA, \{toombsa; gray42\}@purdue.edu \\ ${ }^{2}$ Open Lab, Newcastle University, Newcastle upon Tyne, UK, \\ \{kellie.morrissey; emma.simpson\}@newcastle.ac.uk \\ ${ }^{3}$ Northumbria University, Newcastle upon Tyne, UK, john.vines@northumbria.ac.uk \\ ${ }^{4}$ KTH Royal Institute of Technology, Stockholm, Sweden, balaam@kth.se
}

\begin{abstract}
One of the many challenges of becoming a parent is the shift in one's social life. As HCI researchers have begun to investigate the intersection of sociotechnical system design and parenthood, they have also sought to understand how parents' social lives can be best supported. We build on these strands of research through a qualitative study with new parents regarding the role of digital technologies in their social lives as they transition to parenthood. We demonstrate how sociotechnical systems are entangled in the ways new parents manage their relationships, build (or resist building) new friendships and ad hoc support systems, and navigate the vulnerabilities of parenthood. We discuss how systems designed for new parents can better support the vulnerabilities they internalize, the diverse friendships they desire, and the logistical challenges they experience. We conclude with recommendations for future design and research in this area.
\end{abstract}

\section{Author Keywords}

Parenthood; motherhood; fatherhood; new parents; vulnerability; implicit care; interpersonal relationships; social connection; care work

\section{ACM Classification Keywords}

H.5.m. Information interfaces and presentation (e.g., HCI): Miscellaneous

\section{INTRODUCTION}

There has been a growing attention by HCI researchers in recent years on the ways in which digital technologies support parenting. Studies have explored how social media data might support reflection on individuals changing identities as they transition to becoming a parent [42] and the ways in which communication technologies build confidence and support the portrayal of multiple identities for new

This work is licensed under a Creative Commons Attribution International 4.0 License.

CHI 2018, April 21-26, 2018, Montreal, QC, Canada

(C) 2018 Copyright is held by the owner/author(s).

ACM ISBN 978-1-4503-5620-6/18/04.

https://doi.org/10.1145/3173574.3173994 mothers [18] and fathers [2]. Researchers within and beyond HCI note the various challenges new parents face in terms of transitioning into this new role and maintaining social connectedness [23]. Several studies have highlighted how new parents have a heightened risk of reporting feelings of social isolation as a result of withdrawing from social circles and uncertain patterns of sleep [35, 43]. Indeed, a recent survey noted that $28 \%$ of new mothers experience loneliness following giving birth to their first child [6], which has also been linked with both new mothers and fathers reporting heightened levels of depression [16]. However, despite these studies there is still relatively little understanding of how new parents experience sociality in the days, weeks, and months following the birth of a new child. While work has examined how digital technology supports the sharing of tips, advice, and information related to the care of a newborn, less studied is how sociality and social connectedness is supported by such systems, or indeed how they may alleviate (or amplify) issues of isolation. These issues are becoming increasingly pertinent as entrepreneurs begin to develop applications in this space without a deep understanding of the personal vulnerabilities they may be exacerbating (see, for example, smartphone applications for mothers to find each other, such as Peanut [33] and Mush [30]). Furthermore, in a time when many nations are experiencing a decline in statefunded services and community infrastructures that incidentally supported socialization among new parents, there is a growing demand to identify alternative ways for facilitating connectivity among parents.

In this paper, we report on a qualitative study of the social lives of new parents. Motivated by the above, we conducted our study with a view to exploring with new parents how their social lives were changing, and the role technology played in their experiences. We were particularly interested in understanding the ways in which new parents connect with each other and how such connectivity might be enhanced by the design of future socio-technical systems. To explore these issues, we conducted fieldwork at public events for new parents, interviews with 20 parents across two fieldwork sites, and workshops with 11 participants. The findings from our research foregrounded how new parents manage their relationships and build (or resist) new friendships and ad hoc support systems. We also highlight the ways in which social media can enable social connectivity for new mothers and 
fathers (as per $[2,18]$ ) but can also lead to unhealthy forms of competition and perceptions of judgment among new parents. Through a discussion of our findings, we offer two contributions to the growing body of literature in HCI on parenthood. First, we discuss how thinking through parents' experiences of "vulnerability" as it is entangled in their identities could provide an avenue for re-conceptualizing how sociotechnical systems enable their users to care for each other in implicit ways. Second, we offer a series of recommendations to drive future research and design, focusing on the ways in which systems could be used to manage logistical, emotional, and care labor.

\section{BACKGROUND}

In many UK cities and European nations on the whole, reducing state budgets have prompted the need for certain types of care-particularly interpersonal care-to be facilitated by networks of volunteers, neighbors, and people donating their time for other community members. This shift in the distribution of care labor has sparked numerous arguments, including broad discussions regarding the role of religion in public life [46]; specific arguments against how seemingly-harmless slogans such as "dementia friendly communities" can support a neoliberal cooptation of care labor [34]; and arguments for a new consideration of the role of designers as social innovators [26]. In this study we focus on Newcastle upon Tyne, a city in the North of England. Services that have previously been available to all inhabitants of Newcastle are increasingly only funded in areas that are designated within a certain threshold of "deprivation" [45] as defined by the Index of Multiple Deprivation [17]. Among the services that have been reduced or cut entirely are parenting classes and programs designed specifically to get new parents together in supportive environments. This study is motivated by the push being made to facilitate individuals and groups setting up their own replacements for these services. We ask: how do parents connect with, and support, each other?; What roles do digital technologies and systems play in this process?; and How can future technologies and systems for connecting be designed to better fit into parents' lives?

\section{Related Work}

We situate this study among a body of research within and beyond HCI that engages with the difficulties individuals experience as they transition to parenthood. Descriptions of technological interventions that consider how difficult this transition is have been gaining interest in HCI research [8]. Considerations have included: how the everyday burdens parents face should influence the design of an infant monitoring system [20]; how breast pumps can be better designed to fit into mothers' lives [14]; and how the design of a breastfeeding support system is greatly improved by deliberately engaging with the felt life of breastfeeding mothers [7, 38]. Additionally, social-sharing interventions for parents have appeared within HCI scholarship, including a device for helping parents manage their online presence [42], a system that helps mothers share the physical experience of their pregnancy [21], and a social network for helping single parents connect in person to other parents in their area [5]. Similar applications to the latter design have recently appeared in smartphone app stores, including e.g., Peanut [33] and Mush [30]. While we have not designed such an intervention through this study, the design and deployment of a system for connecting new parents together is part of this project's trajectory.

Beyond the logistical issues and social stigma addressed by the research above, a significant body of work links the transition to parenthood and associated changes in parents' social networks with experiences of depression [12] and social isolation and loneliness [23]. Lee, Vasileiou, and Barnett further linked this social disruption with experiences of "unexpected difficulty and vulnerability," "fewer opportunities for social interaction," and "relationships lacking in desired qualities" [23]. A related strand of research links participation in support groups with improved experiences of these issues. Framing their findings as a way to "reduce demands on overstretched social and health-care services," Nolan et al. described how the friendships formed in perinatal classes can lead to "enhanced self-efficacy because the women give and gain reassurance that their babies are developing normally," so long as the class coordinator takes her role as a networker seriously [32]. Similarly, Leahy-Warren et al. found that informal social support can improve mothers' confidence as well as decrease their risk for postpartum depression by increasing their sense of parental self-efficacy [22]. The value of such informal peer support and, as a result, improved wellbeing, when parents engage in parenting websites and online activities such as blogging has also been well-documented (e.g., [36, 27]). In the discussion section, we will connect these concerns about parents' experiences of vulnerability with the potential for the design of future informal support systems to address those vulnerabilities.

More broadly, research on how parents use social media, and the connection between that usage and parents' identities, has been of increasing interest. Responding to the social exclusion felt by mothers in their early weeks with their children, Gibson and Hanson argue that mothers use technology to reclaim their identities as "more than 'just' a mother" as well as to help improve their confidence as mothers [18]. Ammari and Schoenebeck have studied how fathers use social networking sites in relation to their various roles as fathers, finding that fathers are constrained by their fear of being judged and that they strategically reveal certain parts of their identities as a result of this potential online judgment [2, 3]. Extending this work, Ammari et al. discuss how fathers participate in do-it-yourself (DIY) activities, and then post about those activities online as a way of performing a specific kind of fatherhood identity [4]. Blackwell et al. focus on LGBT parents' use of social media for incidental advocacy work, for identifying allies, and for collectively engaging in privacy practices [9]. Finally, Morris surveyed mothers of young children about their usage of social 
networking sites to determine how this population prefers to share certain types of information, and how those sharing practices change over time [28]. In this paper, we pick up on these identity-related concerns, relating them to parents' experiences forming friends and building community, in addition to parents' experiences of vulnerability.

\section{RESEARCH APPROACH}

This study is part of a larger project which aims to develop systems that will help parents connect with others in their community. In particular, we have been interested in how technologies fit into the complex socio-logistical requirements of transitioning to parenthood. Through this study, we sought to understand the social experiences of parenthood in Newcastle, with a focus on the sociotechnical interactions entangled in those experiences. We conducted the bulk of our fieldwork in Newcastle, but we also interviewed participants in Lafayette, Indiana, a college town in the USA. This secondary context enabled us to develop a reflexive understanding of new parents' experiences in Newcastle, which we will leverage in the next phase of research to design, develop, and document the systems we create in a way that facilitates its transferability to additional contexts. It is not the intention of this project to compare these locations, nor do we wish to form generalizable theory about how new parents connect to their communities regardless of context in this paper. Instead, including two contexts for this study has helped us better understand what is specific about parenting in Newcastle, which helps us ensure: 1) that we are well-placed to create a system that, by its nature, will involve making recommendations for parents in Newcastle that impact their health and wellbeing; and 2) that our future reporting of the systems we develop can be as useful to additional contexts as possible by considering how it can be translated for those contexts instead of decontextually adopted off-the-shelf.

We chose Newcastle as our primary site as part of Open Lab's initiative to explore how technologies can empower citizens and communities, which includes a commitment to local communities, geographies, and civic organizations. We also wanted to capitalize on our proximity to Newcastle in order to build rapport with several key participants relevant to our research interests, including: groups of new parents across multiple regions of the city; individuals in the city's local governmental authority who are involved in organizing and distributing services across the city; and service providers in several of the centers through which new parents access services. We chose Lafayette as our secondary site because we would also be able to build direct access to groups of new parents in that city. The first author lived in and conducted fieldwork in both of these cities throughout the duration of this project.

\section{Data collection and analysis}

We conducted observations, interviews, and workshops with parents, as well as interviews and engagements with service providers and other experts who work with parents and new families. The data for this study were iteratively analyzed using the constant comparative method [11] throughout the data collection process, which spanned a seven month period, as well as in a final analysis stage once data collection was complete. In the following sub-sections, we describe both the data collection and the data analysis in more detail. All fieldwork included in this study was approved by our university's Institutional Review Board and secondarily vetted through discussions with our expert interviewees, who were familiar with our population. Interview and workshops participants were briefed on the project, signed informed consent documents, and were given a $£ 20$ voucher for participating. No real names are used; instead, we refer to our participants with a code that indicates where they participated, whether they identify as a mother or father, and how many children they have. For example, ND2-1 is a Newcastle Dad with one child and LM3-2 is the third Lafayette Mom we interviewed, and she has two children. Participants were recruited through leaflets handed out at community and service centers who were collaborating with us, as well as through word-of-mouth.

\section{Observations, interviews, and engagements}

Throughout our observations, interviews, and engagements there were a number of topics and concerns that drove note taking and questioning. Guiding topics and concerns included: exploring social connectedness and social isolation as experienced by those transitioning to parenthood; the role of space, context, and local community in engaging with parents during this transition; and the role of technologies and sociotechnical systems in brokering these responsibilities. These were informed by prior HCI research in the context of parenthood, as well as previous research engagements we have had in related contexts $[7,15,25,38$, 39]. Observations of public events and groups designed for new parents were recorded through field notes, after obtaining permission from the organizers. Our observations, the conversations we had with organizers, and our initial engagement with the literature in this space informed the composition of our interviews.

Interviews with parents were audio recorded and transcribed, in addition to being recorded through note-taking. These interviews included new parents still transitioning to parenthood (6 in Newcastle, 4 in Lafayette), experienced parents who were reflecting on their own transitions to parenthood ( 3 in Newcastle; 5 in Lafayette), and an expectant parent from Newcastle speculating about how his social life will change when his child is born (ND1-1, whose child was born between his interview and his participation in our workshop). Some interviews were conducted in small groups, resulting in 15 total interviews with 20 total participants from 19 distinct households. The interviews were semi-structured and loosely consisted of three parts: the parent's social life and how it changed or was changing during their transition to parenthood; the role of technology in how their social interactions were coordinated or 
mediated; and the role of their local communities in their social environment.

Engagements with experts in this area took place throughout the study in order to develop a deeper understanding of the larger context in which our population operates, as well as to validate and shape our initial findings. We spoke with three individuals who work for organizations that provide services for parents, a local academic who studies midwifery and was previously a midwife in Newcastle, and two midwives in Lafayette. We were also in regular contact with individuals from Newcastle's local government authority who commission the services mentioned above. These interviews and engagements helped us further understand the impact of decreased state support on services for new parents.

During the data collection period we continually analyzed interview transcripts and notes, observation field notes, and engagement notes through an open coding process. This allowed for the interviews, observations, and engagements to inform each other, as well as for a set of preliminary themes to emerge. These included, for example, "Technology and tech strategies," "Parenting groups," "Social isolation," and "Child care," among others. In the next sub-section, we describe how we incorporated these themes into the design of our workshops.

\section{Workshops}

We conducted two workshops with parents in Newcastle, through which we had seven new participants who were joined by four of our interviewees. Workshops were recorded through field notes and audio recordings, and we held moderator debrief sessions for each workshop. Workshops were designed to be child friendly and several parents brought their children, but the children were explicitly not subjects of the study.

While the workshops served to help us further inquire into participants' experiences, we focused on using them as an early analysis member checking [24] activity. In other words, we structured the three phases of the workshop to help us shape our preliminary findings on the sociotechnical entanglements of new parents' social lives, including technological issues, challenges, and opportunities that our interviewees had discussed with us. In the first phase, we asked participants to discuss quotes we pulled from our interviews, which we selected to represent our preliminary themes discussed in the previous section. We followed this with a technology critique activity in which we prompted participants with descriptions of technologies that also came up during the interview, observation, and engagement phase. These included both existing technologies, such as messaging and social media applications, as well as hypothetical technologies, such as apps that would "match" their families with other families in their local area for potential friendships and playdates. The final phase involved a zine-making activity, through which parents were asked to collaboratively create a zine that could, hypothetically, be handed out to other new families in their neighborhoods, and which focused on the kinds of advice our participants would like those new families to have about how to better connect with others in their areas. The zines helped participants externalize their experiences by orienting their reflections toward "helping" others, enabling us capture additional, nuanced insights.

We used our workshop field notes, the zines generated during the workshops, and our organizer debriefing sessions to inform our axial coding, which involved narrowing, connecting, and re-shaping the themes we saw emerging throughout our data. This second round of coding included such themes as: "Parenting identity," "Vulnerability of parenting," "Informal care competencies," "Interpersonal responsibilities," and "Community culture," among others. We then synthesized these axial codes and the quotes related to them to form the themes we have used to structure the findings and discussion of this paper.

\section{FINDINGS}

We organize our findings under four major themes that were constructed through our analysis of the data we collected: 1) the types of friendships that new parents develop as a direct result of having children, which we call "baby-friends"; 2) the support networks that parents build or are placed in, both online and in person; 3 ) the resistances some parents express toward developing baby-friends or joining such support networks; and 4) feelings of being judged, or as though they are in competition with other parents, and how those feelings are entangled with their identities and experiences as parents.

\section{Making 'baby-friends'}

The most prominent theme throughout our conversations related to the changing nature of our participants' friendships. Many of our participants reflected on how they re-prioritized their relationships after their child's birth:

I think I've had to be a lot more intentional about the friendships that I cultivate, both in terms of starting new ones and keeping old ones, because I have so limited time to be with adults that I only want to be around good ones that help me be better (LD5-2).

This intentionality about his relationships extended to strategies for prioritizing his marriage as well. After describing how active he used to be in a hockey league, he explained how he currently orients his free time: "Once the baby's asleep, we go actually hang out as a couple again, instead of hanging out with buddies or going to play a hockey game. So, that changed a lot" (LD5-2).

LD5-2's reduced capacity for relationships outside of his immediate family was not unique among our participants; others also noted how they tried to make the most of the limited time they now felt they had for socializing. However, what also came through was a will to seek friendships with other new parents. This, in part, was because it was easier to relate to people who are currently going through the same experience you are: 
The stories that they are going through, obviously, you can relate to, because it is fairly recently you have been through, but that is the thing, that is all the chat that happens, it is just kids this, kids that, and we have that same bond. So, it does open up, I guess, new opportunities and you just look at things in different ways (ND2-1).

In some cases, participants explained that having a newborn had led to the formation of friendships with acquaintances they had weak ties with previously:

Before we had our kids [...] we didn't really have anything in common with anyone at the church and all of our friends had left [the city], so it was just the two of us. I think once we actually had our first child was when we started to have more of a common language with the people in the congregation I was serving. I don't know, for some reason it has been a lot easier to have friends now. I think our social life has actually improved since we had kids (LD2-2).

The formation of these new friendships was in part born from the fact that participants found themselves more likely to talk to certain people for no other reason than because they have kids. Despite this seemingly-arbitrary criterion for friendship, it was clear that these relationships could often become genuine and supporting. A consequence of this was that several participants considered their social lives to be better after having children.

Beyond strengthening bonds with weak ties, several of our participants relied on social networking sites and mobile apps to build new friendship groups. Some of these appslike Mush and Peanut-were akin to Tinder, but for new moms. NM5-1 reflected on her experience using Peanut:

It was bizarre! It felt like I was shopping for friends, it was really weird. [...] you were choosing and therefore you may not be chosen. For a new mother who feels a little bit insecure anyway [...] think of those insecurities. You are a new person almost now. You have different pressures, you've got different focusses, you feel differently about yourself as well. The last thing you want is to choose somebody to be your friend, which is what Peanut is asking you to do, and then not be chosen in return! (NM5-1).

Contrasting with this, one workshop participant enjoyed setting up her "mush date":

I wanted to make the best of my maternity, you know, I wanted to have days where I had stuff. And I was interested to meet different people. I didn't want to solely just have my [parenting group] people, because they've got their lives as well. And we're the first ones to have a baby in the family, so I haven't really got anywhere to tap into. One reason I came [to this workshop] was to meet new people (NM7-1).

However, she agreed that "it was a bit like a date," and she and the two people she met through Mush admitted that they "didn't know what to wear" for their meeting.
Critically, even when new parents have developed friendships with other new parents, it can still be difficult for them to coordinate time together. "The complexity of everybody's nap times [and] bed times matching up is just insane" (LD4-1). ND3-2 further explains the logistical issues of being tied to another family's constraints while not being completely sure of one's own restrictions:

There are just so many variables that you have to deal with that it ends up being much easier to say, 'okay if we have all those variables, we'll operate as a unit on our own today, which means we can be responsive, because as soon as we invite somebody along, that means we have to be responsive to their constraints as well (ND3-2).

These challenges become even more acute if breastfeeding:

We were breastfeeding, so that was kind of limiting on where I could go and how far I could go. Even now breastfeeding is fairly controversial so it is not like I can go anywhere [...] I did eventually, but at first that didn't feel very comfortable (LM2-2).

Our participants' difficulties navigating both the logistical challenges as well as the social stigma while breastfeeding and attempting to maintain a social life is consistent with related work, e.g., [7, 14, 18]. While the fathers whose wives were breastfeeding were not socially limited because of a bodily entanglement with their child, they did discuss the guilt associated with justifying their social interactions:

The guys [have to be] like, 'I am going to meet up with some guys so I have some social interaction, you stay at home with the kids some more.' It [...] is inherently unfair if a woman is taking care of the child [alone] (LD4-1).

\section{Joining parenting groups and events}

The relationship development our participants described encompassed more than simply developing individual friendships to also include how they attempted, successfully or not, to join parenting groups or take part in parenting events. It is perhaps because of some of the logistical challenges of creating baby-friends that so many of our participants relied on pre-organized courses and baby groups for their socializing needs, including expensive National Childbirth Trust (NCT) courses or free parenting classes run by local centers or hospitals. These courses and groups are ostensibly about learning practical parenting skills, but most recognize that the friendships one makes through the courses are the primary value [32]. ND4-1 explains his wife's involvement in these kinds of courses: "She chose to go to classes to try and meet some other new soon-to-be mothers. She sees them on a fairly regular basis" and he contrasts this with his own reluctance to participate:

Beforehand, sometimes, I'm just like, I don't know it feels a bit more like a hassle [but] I'm always glad we've gone in the end. It's quite a selfish thing to think, because I do feel like we got something out of it, [My wife] definitely gets something out. Then there will be that reciprocal thing for 
the other parents, as well, like they need positive contributions from everyone else for it to work, so I really need to bear that in mind (ND4-1).

He demonstrates what several of our participants hinted at as a shared responsibility for creating the value these kinds of parenting groups can offer.

While many of our participants in Newcastle relied on these locally-commissioned, pre-organized groups, the funding in place to support them has been consistently diminishing. The local service organizers we spoke with reminisced about the wide variety of courses and events they were able to offer in previous years that specifically engaged with issues of social connectedness among new parents. Notably, a cakedecorating class that is now only offered in areas of high deprivation used "cake decorating" as an excuse to get local women together to socialize (and, in some cases, practice their English). A related service called "Time to Talk" sought to provide parents with a space to sit and chat while their children were looked after in free child care, but it has been defunded because it could not be framed as a practical skillsbuilding exercise.

Several of the advice zines generated in the workshops responded to Newcastle's reduced capacity to provide these services by including practical advice for how to find events in one's local area; the kind of advice that our participants would have liked to have received. This included how to ensure an event is convenient and financially justifiable, as well as how to tell if the event will be a good fit for their family. This is consistent with Gibson and Hanson's findings that parents can often be frustrated by how difficult it is to find "community groups meeting within their local area" that were more than just "structured classes that were run as businesses" [18].

Even though most recognized the relationship-building value of these kinds of groups, the size of the group seemed to make or break the experience. Several participants reflected on how they struggled with finding people 'like them' at activity sessions or parent meet-ups because they would become overwhelmed with groups that were too large. Others noted that they would not go to parenting events or groups unless a "closer friend" went with them, or they would make sure that someone they already knew would be at an event. LD4-1 walks us through a typical experience for him, explaining why he thinks large parenting events often fail at forming a "community":

You [try to] find out if anyone else you know is going and the answer is always, "Maybe." Then you get there and you don't see anyone you know and there are like $100 \mathrm{kids}$ you don't know. They go around and get balloon pop things and stuff for the kids to play with. [...] You get your coupon and then you go home. [...] You don't really build any community, but you had kind of a fun night and maybe you saw one person you knew. They are events that don't really encourage long-term relationships. They are just one-offs that are fun to do, which is a good thing. I think on the whole people need to have a plan for long-term community building for themselves (LD4-1).

Developing this feeling of community was important for our participants, and many discussed how they would enjoy participating in a smaller, locally focused community, so long as they did not have to do the coordinating work themselves: "I like my neighbors when I get to talk to them, but it's just somebody else has to set something up, because I've got other shit to do" (LD5-2). After one participant in a group interview described how he thinks these community formation and coordination issues are a modern problem, LM2-2 related a friend's story:

I know somebody who is a first-time parent in his 50s [...]. He was like, 'How do you meet other parents? What do you people do together? Back in the day we'd have had a pot luck and invited a bunch of people over, but that doesn't seem to be a thing anymore.' It raises an interesting question of he knew a community that he would have raised children in, but now he is in one where he doesn't know where to go for those things (LM2-2).

While these community-building practices were noted by our participants as lacking in secular culture, they seem to be continued through more traditional religious cultures:

We had the good fortune to be part of a church that already basically had a routine for people that had new babies. At the same time we were staying home and sleeping a lot they were delivering meals and coming to visit just to say hi. There were people who were planning for us to be isolated who would come in and look after us (LD4-1).

These gaps in community coordination capacity are partially, though currently inadequately, filled by apps and websites like Hoop and Facebook, or by group messaging apps such as WhatsApp and Facebook Messenger. Hoop is a smartphone application designed for finding events for kids in a specific area, and a few of our participants use the app when they remember to open it up and look for one-off events. Facebook was mentioned much more frequently as a resource for finding activities to do as a family, and part of this was attributed to an element of serendipitous discoverability of those events. Even our expectant father anticipated making use of these features:

They get those notifications that say, 'So and so is attending an event near you.' It's always like the new parents that I know who are attending some kind of Easter egg hunt [...] I probably would find that out from Facebook (ND1-1).

Several participants in the workshops also mentioned enjoying the low bar for marking their interest in events on Facebook, as it did not represent a firm commitment so they could avoid feeling guilty if they had to cancel.

Beyond finding events through social networking sites, our participants also mentioned the online social groups they had become a part of. Parents' participation in these kinds of 
online groups has been studied widely (e.g., [2, 22, 23]). However, we highlight here that, consistent with Gibson and Hanson's study of parenting on Facebook [18], many of our participants discussed the comfort they experienced in knowing that if they were up at 2 am with their child, they could post in an online group without fear of disturbing anyone else's sleep, and still be able to get a response from someone who happened to be in the same situation.

\section{Resistance to 'baby-friends' and parenting groups}

What we have presented so far has been an optimistic view toward how parents perceive developing "baby-friends" and the possibilities of joining groups of other parents, despite the associated challenges. However, not all of the participants felt comfortable with these new friendships and social ties they were forming after becoming a parent. In some cases, participants worried about the ways in which they could form bonds and connections with other new parents. Our expectant father speculated that he would have a hard time making small talk with his child's classmate's parents because "the only thing that you've got in common is the fact that you have children" (ND1-1). The issue of having to make small talk resonated in many of the interviews. For some participants, there was a feeling that these relationships were weak and happenchance in nature, with people becoming connected through an arbitrary commonality. For example, NM5-1 described how she avoids some of her 'baby-friends' she met through an NCT course, connecting this to a competitiveness she experienced through those kinds of relationships:

And that really was buying friends. [...] I'd heard of lots of people in the past who've met some friends for life through $N C T$, oh [interviewer name]! It couldn't be further from the truth where it came to my experience. I'm sure these people ate their own placenta, they were proper weird! [...] I'll meet them for a coffee, that's fine, but I'm not going to be bosom buddies with them. The only thing we have in common is that we all have children round about the same [age]...but again, straight away, 'oh isn't she so small, god, look at mine, he's massive' and I'm like ' $\mathrm{hmmm}$ ' (NM5-1).

The personalities involved in the group can make or break how successful the group is at fulfilling the shared responsibility of creating value through the group's activity. This extends to the issues several fathers discussed as a general unwillingness among other dads to participate:

The guys who went to those [groups] were always kind of stand-offish because they were just tagging along with their wives. They were like, 'She said I had to be here.' 'Yes, me too.' 'Do you want to have a beer?' 'Yes.' That is like the extent of your interaction (LD4-1).

We found a similar reluctance to participate through social media, despite recognizing the important functions it can perform: "I kind of shoot myself in the foot because I don't use the tools that are available to arrange these kinds of things" (ND3-2). Some were not interested in merging the superficiality they had experienced through online social networks with their "real lives," particularly if they had previous negative experiences that were not easy to share:

For me I didn't really want to be a part of that whole feast and famine emotional pain and emotional joy environment. I would much rather disconnect my actual life. I will talk about that with friends and people I know personally, but I would rather not have every minor acquaintance I have got on Facebook be chiming in on whether or not we were able to conceive this year. [...] I just feel like a lot of my online life is fun, but I try to deliberately keep it superficial (LD4-1).

Beyond this reluctance to use social media for coordinating events or groups was a more intentional avoidance of online group communication due to issues with untrustworthyinformation-sharing, fear-mongering, and echo-chambering that could take place in those spaces:

I'm not as interested in online support groups. I know that there are a lot of those and moms share information and experiences but I'm the type of person who much more values interaction in person. I kind of, seek out those opportunities and try to avoid online support groups because they can be overwhelming. It's full of information which is mostly opinion based (LM1-1).

Similar concerns have been discussed in related work on information sharing in care-based contexts [7, 29, 44].

Through these examples, it becomes clear that the formation of new friendships could be challenging for new parents, as they seek ways of finding resonances with others based on their interests, personality, and outlook on life. Entangled in, but also extending beyond, the resistances discussed in this section are the interpersonal and social tensions our participants felt, toward which we now turn our attention.

\section{Competition, judgment, and "super parent" identities}

An underlying theme that pervaded our participants' negative social experiences was the perception that they were being judged for their parenting abilities, either directly through judgmental remarks, or indirectly through comparisons made between their experiences and others'. This was often accompanied by the perception that other parents were trying to beat them in an involuntary and invisible competition. LD5-2 explained, for example, that he would rather do "dad things" with his kids than take them to a mommy playgroup because, for him, parents use those kinds of groups as "a way to show off [their] kids."

In our data, these feelings of judgment and competition surfaced in a variety of ways, including how parents compared their children's' sizes, if they were having issues conceiving, how "mother earth" their parenting styles were, whether they paid for NCT courses or took the free equivalent versions, how well they were sleeping, whether they were breastfeeding, and even how "keen" they were to be participating in parenting events (where both being too keen and not being keen enough would be judged). The 
feeling of being judged, and the associated barriers with those judgments, have been documented in parenthood literature in $\mathrm{HCI}$ (see, e.g., [2, 3, 9]).

In response to the capacity for other parents to judge, LM32 described her criteria for choosing baby-friends, citing how important it is to be able to be candid with them rather than participate in an implicit parent-off:

My favorite relationships that have formed around parenthood are the ones where I can call my kid an asshole sometimes. When you find that person and you know that it's a safe place and you can be candid it is one of the biggest things that has got me through motherhood. [...] I think that can be really healthy (LM3-2).

However, establishing a candid relationship with another parent does not seem to be a permanent boundary, but rather one that must be constantly crossed and negotiated. LM4-1 describes how even in her small group of baby-friends where she has established a precedent of sharing vulnerable stories, she is consistently the first to share her negative experiences:

On the [Facebook] group if I shared, that's when other people would share. I remember I was about nine months pregnant and I was going through one of those days where I was just crying. Literally I woke up in the morning and I don't know if it was hormones or anxiety of delivery, I don't know. I just wrote this huge post and I was like, 'I don't know but I'm just crying all day and everything.' Then my friend who had her baby before me she was like, 'Oh my God, about this time, I felt the same way. I went through a breakdown.' Then somebody else shared that they had a breakdown too, so I was like, 'If I hadn't really shared this, other people wouldn't have shared.' (LM4-1)

Even if parents become comfortable negotiating those explicit boundaries around venting, the larger barrier of asking others for help can still seem insurmountable. Several participants cited the boundaries that pleasantries, social etiquette, and scripts of behavior can create for social interactions. The social obligations of receiving care from one's friends, for example, can make asking for that care or that support more inconvenient and, for some, not worth asking for. LM1-1 elaborates on this double burden:

And to some extent I find all of these pleasantries and 'appropriate behaviors' really frustrating and annoying because it would be nice if we could just kind of toss that aside and just be real and say 'yeah, I do-can you just go and do this for me' and if they're busy they can just be like 'actually, I can't right now but you know hit me up next time' [...] but I know we tend to get caught up on (interviewer: 'pleasantries and social obligations?') yeah and I guess those scripts of behavior where somebody says 'what can I do for you' and you say 'oh nothing I'm fine' when in reality... (LM1-1).

The desire to be able to enact social pleasantries, including "proper" displays of gratitude, can set a high bar for social interactions for new parents. These experiences of being held to a higher standard are also likely intertwined with gender roles and expectations; after ND1-1 explained that he would not likely ask a friend for help unless he was in desperate need of it, he speculated about how his wife would feel:

She'd be mortified even if she wanted it, I think, to ask somebody for help. [...] The social etiquette thing is so strong. She's worried about people wanting to come and visit and help; and her being so tired and distracted. Not being able to thank them properly, and make them feel like that's doing a good thing. So, she'd feel like she'd rather not have someone round, than to have someone round and not be able to be a good host (ND1-1).

These experiences are entangled in several tensions that new parents hold, including the desire to be independently capable, maintain one's identity outside of parenthood, and be appropriately grateful when they do have to depend on someone else; in short, the desire to be a super parent.

These super parent desires were tied to our participants' own critical and judgmental behaviors as well. Just as almost all of our participants had some kind of negative experience to share in which they were on the receiving end of another's judgment or criticism (both perceived and real), so too did they also exhibit those critical and judgmental behaviors. In describing why she did not bond well with others in her NCT course, we saw above how one participant called her potential peers "proper weird," and several of our participants consistently commented on the "types of people" you can meet at parenting events.

This co-participation in the reproduction of judgmental behaviors among parents is likely linked to how the ideal of being a super parent is entangled in a parent's identity. Several participants in the workshop discussed that in becoming a parent "you lose your identity as a person as well," and these concerns about having an identity beyond that of a parent are further discussed in Gibson and Hanson's research [18]. We saw this judgment-and-identity complication play out in how our expectant father, ND1-1, discussed why he thinks he would not post images of his child online for fear of losing his identity:

I would never put a picture of my kid up on Facebook I don't think. We didn't even announce our pregnancy or anything on there. I would keep our life out of it, but then just consume [from] other people. [...] My reservations don't come from ownership of images, consent, privacy, security, or any of that stuff. They've come from seeing other people do it and thinking, 'God, you are boring. I do not want to be like you.' Sorry. I just see these people who just become professional parents and I just don't want that to be me at all. It's like all they are is their kids (ND1-1).

We were fortunate to have a wide range of parent identities represented among our participants. LM3-2, for example, freely admits that "being a mom" was her primary identity: 
I think I have been the kind of parent that [other participant] said earlier. I don't know what you called it, that you define yourself by [being a parent]. I did that, I was like, 'This is me now.' I was all in 100\% mom now. [...] I don't think I had enough of an identity for myself when my first was born to separate. I was still figuring out who I was (LM3-2).

Finally, circling back to our interest with how these tensions relate to parents' abilities to engage socially, NM5-1 describes her cautious approach to making baby-friends because she wanted to guard how she sees herself:

I like who I am and I don't really want to change that too much. And I haven't actually met that many other mother friends as in new mums at the minute who have babies like I do. But the ones that I have met...they're nice people, they're just maybe not the kind of people that I would usually choose as friends. So I think 'well if I wouldn't usually choose them before I had a baby then why would I choose them just because I have got a baby' (NM5-1).

\section{DISCUSSION}

In this final section, we discuss how thinking through parents" experiences of "vulnerability" as it is entangled in their identities could provide an avenue for reconceptualizing how sociotechnical systems enable their users to care for each other in implicit ways. We conclude with recommendations to drive future research and design in this space, focusing on the ways in which systems could be used to manage parents' logistical, emotional, and care labor.

\section{Navigating parenthood vulnerabilities}

Our data corroborate the findings of related scholarship that as new parents' social networks change, they can experience feelings of depression, isolation, and loneliness [12, 22], but we have also demonstrated how some parents take advantage of the instability of their social networks to build new connections and, occasionally, improve their social lives. However, whether they perceive these social changes positively or negatively, many parents are met with "unexpected vulnerabilities" [23] and insecurities throughout this relationship- and community-building process. This leads us to a perhaps naively-generalized question: how can we, as researchers and designers of the sociotechnical systems which these parents use to connect to each other, be more sensitive toward the vulnerabilities and insecurities they face? Applications that take the desire of parents to meet others like them in their area at face value, such as Peanut and Mush, are beginning to surface in smartphone app stores. While acknowledging their theoretical usefulness, our participants felt awkward using these apps, not just because they were apps or because they resembled dating systems, but because their insecurities about whether or not they would be "chosen" by someone else was intimately tied to the vulnerability of their shifting identities as parents and as individuals.

More broadly, several participants discussed how they were reluctant to share their difficult parenting experiences on social media. LD4-1 referred to the "feast and famine" environment of Facebook he and his wife had to actively avoid while they were experiencing difficulties conceiving. This negotiation of what to disclose is consistent with Newman et al.'s work on how individuals with significant health concerns balance managing their self-presentation through social media with sharing information online about their needs [31]. While the pressure new mothers feel to refrain from admitting to negative emotions is well documented [23], the constantly renegotiated boundaries of what vulnerabilities parents can and cannot share, even among intimate friend groups such as with LM4-1's babyfriends, warrants further investigation.

One way to facilitate this type of analysis, which we will pick up in future work, is to leverage Toombs et al.'s call for care in HCI research to be used both as an analytical lens in studies of communities and as a designerly lens in the development of interventions that support the interpersonal maintenance of those communities [39]. We echo and extend that call here to include a specific consideration for how personal vulnerabilities are experienced or are mitigated through interpersonal, implicit care (or, care that is felt but not explicitly communicated [13]). Incorporating these analytical strategies could lead to further insight into how the design of a sociotechnical system can be leveraged to reduce the potential for judgmental or competitive behaviors among its participants. It is unlikely that any parent is immune to contributing to the reproduction of judgmental and competitive environments, despite understanding how it feels to be the one who is judged. However, certain environments may better afford those negative behaviors, where by "environment" we concern ourselves with both specific interface details as well as strategies for framing participation. For example, LM3-2 described how the hybrid online/offline group she organizes makes use of "off-topic" threads "where they talk about different aspects of parenting, challenges, and what you are up against" (LM3-2) in their community to preclude judgmental and critical behaviors in an explicit way. On an individual level, participants in that group who write posts that begin with, "I'm not looking for a debate" explicitly ask for support but not for criticism. Relatedly, NM5-1 suggested that parenting apps and websites could benefit from incorporating something as simple as humor to mitigate some of these felt vulnerabilities and insecurities, "Come and meet other mothers that are also sleep-deprived!" (NM5-1). Through these and other examples it is clear that there is value in explicitly supporting candid (or humorous) conversations to reduce the potential for judgmental and competitive interactions (see [1] for an example of this principle in action).

However, we argue that focusing on vulnerabilities and implicit care interactions in this way can go beyond simply attempting to mitigate negative interpersonal experiences to something that is leveraged to help parents connect together on a deeper level. One of our expert interviewers explained that she often frames the programs and parent get-togethers 
she organizes in such a way that the participants feel as though they are helping others by going. When they feel like "helpers" rather than "people in need of help," they are more encouraged to attend. How could this be translated to a digital context? This insight draws together care ethics research about how we are all interdependent beings that require care and desire to perform care [41] as well as Gibson and Hanson's findings that mothers desire to be able to extend their identities beyond that of "just" being a mother [18]. Designing for parents' vulnerabilities could provide an avenue for understanding how to design for the vulnerabilities of other populations as well, as HCI researchers and designers learn to navigate these interpersonal, implicit care needs of individuals. As Brené Brown says, "vulnerability is the core, the heart, the center, of meaningful human experiences" [10].

\section{Managing logistical, emotional, and care labor}

Through orienting our thoughts towards the broader conceptual goals presented in the previous section, we next develop several practical directions for future design and research that could begin to address the need to help parents manage their entangled logistical, emotional, and care labor. In the context of reduced funding for state-supported parenting services, technologies that can ease the burden being offloaded onto parents will be in high demand. We do not support funding reductions for those in need, and we believe it should not be the responsibility of technology to do the job of a government which those individuals have paid for via taxes, especially when those technologies require time and effort on the behalf of people using them. Nevertheless, it is better that we are prepared for the possibility that such systems will be necessary.

Because of their reduced capacity for building relationships outside of their families, empathy from others is a highpriority criterion for new friendships that new parents develop [23]. A practical suggestion we have for systems being developed to support new parents who live geographically near each other is that they focus more on facilitating the creation and maintenance of small group interactions that provide safe spaces for guilt-free (if that is even possible) sharing of parenting experiences. While prior work has found that such disinhibited safe spaces can exist in anonymous or pseudonymous social sites for parents [37, 2], further research is needed to understand how nonanonymous small groups could enjoy similar benefits. If done successfully, such systems could also open up the possibility of helping parents cultivate diverse friendships with others who may not be in the same circumstances, but who could prove to be just as empathetic. Currently, there is little support for helping parents develop cross-gender friendships, inter-generational friendships, or friendships with childless others. Successful models of similar systems can be found in more organized groups, such as religious communities and neighborhoods that host regular pot-lucks. These groups seem to have well-developed structures and routines in place for supporting the transition to parenthood that can shape the friendships and experiences those parents have. What these successful strategies share is their focus on small group interactions of people who are likely to understand and empathize with the struggles of transitioning to parenthood, and they provide an "excuse" other than loneliness for getting together.

As we saw in our data, developing a feeling of community takes a significant amount of coordination work as well as sustained interpersonal effort. Once these groups are established, the responsibility of maintaining the value of participating in them is shared by the participants and the organizers of those groups [32]. In this case, the "organizer" could very well be a set of algorithms, but that responsibility does not disappear. How a non-human entity could fulfill this role will have to be explored in future work, but it could include: building in explicit structures for participants to interact candidly or humorously with each other; helping parents navigate around the social etiquette of asking for help from their friends (but without transforming those from relational to transactional interactions); emphasizing lowobligation participation (e.g., "dress code is comfy clothes); or helping parenting friends casually bump into each other in a low-barrier way.

We conclude with practical advice for researchers who hope to engage with parents in their studies, as well as for individuals who organize events, courses, or workshops for new parents: save time in the schedule for socializing. We found that one of the primary motivations our parent participants had for joining our study was to be able to vent to the interviewer, or to be able to meet other parents in the workshops. These research engagements can serve as an opportunity for participant self-reflection and provide helpful, "healing" moments for them [19, 40].

\section{CONCLUSION}

In this paper, we have provided further insight into the technological support needs of new parents, building upon previous research into the difficulties individuals experience as they transition to parenthood. Through extensive qualitative engagement, we have identified several areas where technological support is needed, particularly as governments reduce funding for social support. Our analysis of these areas provides multiple opportunities for future technological innovations that build on these known barriers that parents experience, foregrounding aspects of interpersonal care and vulnerability that are important in building and maintaining parenting relationships.

\section{ACKNOWLEDGMENTS}

We would like to thank our community collaborators, our participants, their families, and our reviewers. This research was funded in part by the EPSRC Digital Economy Research Centre (EP/M023001/1) and the EPSRC CDT in Digital Civics (EP/L016176/1). Data supporting this publication is openly available under an 'Open Data Commons Open Database License'. Additional metadata record at http://dx.doi.org/10.17634/154300-66. 


\section{REFERENCES}

1. Teresa Almeida, Gavin Wood, Dean Saraf, and Madeline Balaam. 2015. Labella. In Proceedings of the 2015 British HCI Conference (British HCI '15). ACM, New York, NY, USA, 310-311. DOI: http://dx.doi.org/10.1145/2783446.2783626

2. Tawfiq Ammari and Sarita Schoenebeck. 2015. Understanding and Supporting Fathers and Fatherhood on Social Media Sites. In Proceedings of the 33rd Annual ACM Conference on Human Factors in Computing Systems (CHI '15). ACM, New York, NY, USA, 1905-1914. DOI: https://doi.org/10.1145/2702123.2702205

3. Tawfiq Ammari and Sarita Schoenebeck. 2016 "Thanks for your interest in our Facebook group, but it's only for dads": Social Roles of Stay-at-Home Dads. In Proceedings of the 19th ACM Conference on Computer-Supported Cooperative Work \& Social Computing (CSCW '16). ACM, New York, NY, USA, 1363-1375. DOI: https://doi.org/10.1145/2818048.2819927

4. Tawfiq Ammari, Sarita Schoenebeck, and Silvia Lindtner. 2017. The Crafting of DIY Fatherhood. In Proceedings of the 2017 ACM Conference on Computer Supported Cooperative Work and Social Computing (CSCW '17). ACM, New York, NY, USA, 1109-1122. DOI:

https://doi.org/10.1145/2998181.2998270

5. Sinan E. Arkonac, Joe Frazer, Ryan John Horgan, Anna Kracewicz, and Latefa Al-Naimi. 2017.

"ParentCircle: Helping Single Parents Build a Support Network." In Proceedings of the 2017 CHI Conference Extended Abstracts on Human Factors in Computing Systems. CHI EA '17. ACM.

http://doi.acm.org/10.1145/3027063.3049271

6. AXA PPP healthcare. 2015. Overcoming feelings of isolation as a new parent: Online survey of 3,000 UK mums conducted during January 2015 by Netmums. Retrieved on September 18, 2017 from: https://www.axappphealthcare.co.uk/healthworries/pregnancy---childcare/article/overcomingfeelings-of-isolation-as-a-new-parent/

7. Madeline Balaam, Rob Comber, Ed Jenkins, Selina Sutton, and Andrew Garbett. 2015. FeedFinder: A Location-Mapping Mobile Application for Breastfeeding Women. In Proceedings of the 33rd Annual ACM Conference on Human Factors in Computing Systems (CHI '15). ACM, New York, NY, USA, 1709-1718. DOI:

https://doi.org/10.1145/2702123.2702328

8. Madeline Balaam, Judy Robertson, Geraldine Fitzpatrick, Rebecca Say, Gillian Hayes, Melissa Mazmanian, and Belinda Parmar. 2013. Motherhood and HCI. In CHI'13 Extended Abstracts on Human
Factors in Computing Systems (CHI EA '13). ACM, New York, NY, USA, 3215-3218. DOI: https://doi.org/10.1145/2468356.2479650

9. Lindsay Blackwell, Jean Hardy, Tawfiq Ammari, Tiffany Veinot, Cliff Lampe, and Sarita Schoenebeck. 2016. LGBT Parents and Social Media: Advocacy, Privacy, and Disclosure during Shifting Social Movements. In Proceedings of the 2016 CHI Conference on Human Factors in Computing Systems (CHI '16). ACM, New York, NY, USA, 610622. DOI: https://doi.org/10.1145/2858036.2858342

10. Brené Brown. Daring greatly: How the courage to be vulnerable transforms the way we live, love, parent, and lead. Gotham, 2012.

11. Juliet Corbin and Anselm Strauss. Basics of qualitative research. Sage, 2014.

12. K. K. Bost, M. J. Cox, M. R. Burchinal, and C. Payne. 2002. Structural and supportive changes in couples' family and friendship networks across the transition to parenthood. Journal of Marriage and Family, 64(2), 517-531. DOI: 10.1111/j.1741-3737.2002.00517.x

13. Barbara Dennis, publishing as Barbara Korth. 2003. A Critical Reconstruction of Care-in-Action. The Qualitative Report 8, 3.

14. Catherine D'Ignazio, Alexis Hope, Becky Michelson, Robyn Churchill, and Ethan Zuckerman. 2016. A Feminist HCI Approach to Designing Postpartum Technologies: "When I first saw a breast pump I was wondering if it was a joke". In Proceedings of the 2016 CHI Conference on Human Factors in Computing Systems (CHI '16). ACM, New York, NY, USA, 26122622. DOI: https://doi.org/10.1145/2858036.2858460

15. Andrew Dow, Rob Comber, and John Vines. 2018. Between Grassroots and the Hierarchy: Lessons Learned from the Design of a Public Services Directory. Proceedings of the 36th Annual ACM Conference on Human Factors in Computing Systems (CHI '18). ACM, New York, NY, USA. DOI: https://doi.org/10.1145/3173574.3174016

16. M. Edhborg, A. Matthiesen, W. Lundh, \& A. Widström. 2005. Some early indicators for depressive symptoms and bonding 2 months postpartum - a study of new mothers and fathers. Archives of Women's Mental Health, 8(4), 221-231. DOI: https://doi.org/10.1007/s00737-005-0097-5

17. English indices of deprivation 2015. 2015. Retrieved on September 18, 2017 from:

https:/www.gov.uk/government/statistics/englishindices-of-deprivation-2015

18. Lorna Gibson and Vicki L. Hanson. 2013. Digital motherhood: how does technology help new mothers?. In Proceedings of the SIGCHI Conference on Human Factors in Computing Systems (CHI '13). ACM, New 
York, NY, USA, 313-322. DOI:

https://doi.org/10.1145/2470654.2470700

19. Grace Giorgio. 2013. Chapter Twenty-Two: Trust. Listening. Reflection. Voice: Healing Traumas through Qualitative Research. Counterpoints 354: 459-74. http://www.jstor.org/stable/42981182

20. Gillian R. Hayes, Donald J. Patterson, Mohan Singh, Dana Gravem, Julia Rich, and Dan Cooper. 2011. Supporting the transition from hospital to home for premature infants using integrated mobile computing and sensor support. Personal Ubiquitous Computing. 15, 8. 871-885. DOI: http://dx.doi.org/10.1007/s00779011-0402-4

21. Mary Hui, Christine Ly, and Carman Neustaedter. 2012. MammiBelli: sharing baby activity levels between expectant mothers and their intimate social groups. In CHI '12 Extended Abstracts on Human Factors in Computing Systems (CHI EA '12). ACM, New York, NY, USA, 1649-1654. DOI: http://dx.doi.org/10.1145/2212776.2223687

22. Patricia Leahy-Warren, Geraldine McCarthy, and Paul Corcoran. 2012. First-time Mothers: Social Support, Maternal Parental Self-efficacy and Postnatal Depression. Journal of clinical nursing 21, no. 3-4: 388-397.

23. Lee, Katharine, Konstantina Vasileiou, and Julie Barnett. 2017. "'Lonely within the mother': An exploratory study of first-time mothers' experiences of loneliness." Journal of health psychology: 1359105317723451.

24. Yvonna S. Lincoln and Egon G. Guba. 1985. Naturalistic inquiry. Sage Publications, Beverly Hills, CA.

25. Kiel Long, Lyndsey L. Bakewell, Roisin C. McNaney, Konstantina Vasileiou, Mark Atkinson, Manuela Barreto, Julie Barnett, Michael Wilson, Shaun Lawson, and John Vines. 2017. Connecting Those That Care: Designing for Transitioning, Talking, Belonging and Escaping. In Proceedings of the 2017 CHI Conference on Human Factors in Computing Systems (CHI '17). ACM, New York, NY, USA, 1339-1351. DOI: https://doi.org/10.1145/3025453.3025715

26. E. Manzini and R. Coad. 2015. Design, when everybody designs: An introduction to design for social innovation. MIT press.

27. B. T. McDaniel, S. M. Coyne, and E. K. Holmes. 2012. New Mothers and Media Use: Associations Between Blogging, Social Networking, and Maternal WellBeing. Maternal and Child Health Journal, 16(7), 1509-17.

28. Meredith Ringel Morris. 2014. Social networking site use by mothers of young children. In Proceedings of the 17th ACM conference on Computer supported cooperative work \& social computing (CSCW '14). ACM, New York, NY, USA, 1272-1282. DOI: http://dx.doi.org/10.1145/2531602.2531603

29. Kellie Morrissey, Andrew Garbett, Peter Wright, Patrick Olivier, Edward Ian Jenkins, and Katie Brittain. 2017. Care and Connect: Exploring DementiaFriendliness Through an Online Community Commissioning Platform. In Proceedings of the 2017 CHI Conference on Human Factors in Computing Systems (CHI '17). ACM, New York, NY, USA, 21632174. DOI: https://doi.org/10.1145/3025453.3025732

30. Mush website. https://www.letsmush.com Accessed: September 18, 2017.

31. Mark W. Newman, Debra Lauterbach, Sean A. Munson, Paul Resnick, and Margaret E. Morris. 2011. It's not that I don't have problems, I'm just not putting them on Facebook: challenges and opportunities in using online social networks for health. In Proceedings of the ACM 2011 conference on Computer supported cooperative work (CSCW '11). ACM, New York, NY, USA, 341-350. DOI:

https://doi.org/10.1145/1958824.1958876

32. M. L. Nolan, V. Mason, S. Snow, W. Messenger, J. Catling, and P. Upton. 2012. Making Friends at Antenatal Classes: A Qualitative Exploration of Friendship Across the Transition to Motherhood. The Journal of Perinatal Education, 21(3), 178-185.

33. Peanut website. https://www.peanut-app.io Accessed: September 18, 2017.

34. Rahman, R. 2015. Dementia-Friendly Communities and the Big Society. Accessed May 16th: http://dementiasoc.org.uk/other/dementia-friendlycommunities-and-the-big-society-my-pledge-fornhschangeday/

35. Kantar Republic. 2016. Trapped in a bubble: An investigation into triggers for loneliness in the UK. Retrieved from:

http://www.redcross.org.uk/ /media/BritishRedCross/ Documents/What $\% 20 \mathrm{we} \% 20 \mathrm{do} / \mathrm{UK} \% 20$ services/Co_O p_Trapped_in_a_bubble_report_AW.pdf

36. A. Sarkadi and S. Bremberg. 2004. Socially unbiased parenting support on the Internet: a cross-sectional study of users of a large Swedish parenting website. Child: Care, Health and Development 31, 1, 43-52.

37. Sarita Yardi Schoenebeck. 2013. The Secret Life of Online Moms: Anonymity and Disinhibition on YouBeMom.com. Proceedings of the International AAAI Conference on Weblogs and Social Media (ICWSM 2013), 555-562.

https://www.aaai.org/ocs/index.php/ICWSM/ICWSM1 3/paper/viewFile/5973/6395

38. Emma Simpson, Andrew Garbett, Rob Comber, and Madeline Balaam. 2016. Factors Important for Women 
Who Breastfeed in Public: A Content Analysis of Review Data From FeedFinder. BMJ open 6, no. 10, e011762.

39. Austin L. Toombs, Shaowen Bardzell, and Jeffrey Bardzell. 2015. The Proper Care and Feeding of Hackerspaces: Care Ethics and Cultures of Making. In Proceedings of the 33rd Annual ACM Conference on Human Factors in Computing Systems (CHI '15). ACM, New York, NY, USA, 629-638. DOI: https://doi.org/10.1145/2702123.2702522

40. Austin L. Toombs, Shad Gross, Shaowen Bardzell, and Jeffrey Bardzell. 2017. From Empathy to Care: A Feminist Care Ethics Perspective on Long-Term Researcher-Participant Relations. Interacting with Computers, Volume 29, Issue 1. 45-57, DOI: https://doi.org/10.1093/iwc/iww010

41. Joan C. Tronto. 1993. Moral Boundaries: A Political Argument for an Ethic of Care. Routledge, New York, New York.

42. Diego Trujillo-Pisanty, Abigail Durrant, Sarah Martindale, Stuart James, and John Collomosse. 2014. Admixed portrait: reflections on being online as a new parent. In Proceedings of the 2014 conference on Designing interactive systems (DIS '14). ACM, New
York, NY, USA, 503-512. DOI:

https://doi.org/10.1145/2598510.2602962

43. Janet Ubido and Alex Scott-Samuel. 2014. Loneliness (Rapid Evidence Review Series). Liverpool Public Health Observatory. Retrieved from:

https://www.champspublichealth.com/sites/default/files /loneliness $\% 20$ final.pdf

44. John Vines, Peter C. Wright, David Silver, Maggie Winchcombe, and Patrick Olivier. 2015. Authenticity, Relatability and Collaborative Approaches to Sharing Knowledge about Assistive Living Technology. In Proceedings of the 18th ACM Conference on Computer Supported Cooperative Work \& Social Computing (CSCW '15). ACM, New York, NY, USA, 82-94. DOI:

http://dx.doi.org/10.1145/2675133.2675222

45. Ward funding, Newcastle upon Tyne Wards. Last accessed 29 December 2017.

https://www.newcastle.gov.uk/communities-andneighbourhoods/grants-and-funding/ward-committeefunding

46. R. Williams. 2015. Faith in the Public Square. London: Bloomsbury Continuum. 